Józef Stala

The Pontifical University of John Paul II in Cracow, Poland

\title{
Der Mensch als Person: Die bestimmende Grundlage für Johannes Paul II. in seinem Bild von der Familie
}

\author{
The Human Being as a Person: \\ The Primary Determinant for John Paul II in His Vision of the Family
}

Abstract

Pope John Paul II frequently describes humans in terms of personal being. One could say that this is one of the most fundamental aspects in his teaching. This text analyses the anthropology underlying his papal teaching in the context of the modern world and modern family life. The author emphasizes that the contemporary context reflects a multifaceted crisis affecting humans. The text explores a core aspect of Pope John Paul II's teaching in his vision of the family, which is the issue of how to understand the human being as a person. Fundamentally the family is presented as a communion of persons, then a person is shown as the primary determinant in family education.

\section{Keywords}

John Paul II, human being, person, family.

Der Mensch ist als Person $\mathrm{zu}$ betrachten. Diese Grundannahme war prägend für das gesamte Lehrwerk Papst Johannes Pauls II., denn sowohl seine Ausführungen im philosophisch-theologischen als auch im seelsorgerischen Bereich sind davon inspiriert. Bereits als Bischof war K. Wojtyła von der Mystik der Schwester Theresa von Avila und des heiligen Johannes vom Kreuz fasziniert und strebte danach, das Mysterium des Menschen im karmelitischen 
Geist weiter zu entschlüsseln ${ }^{1}$. In der Zeit seines Pontifikats befasste er sich in einer Vielzahl von Schreiben mit einer Anthropologie, deren Wesen im Personalismus begründet ist. Dabei beleuchtete er alle Aspekte des menschlichen Lebens, insbesondere die Krisen und Gefährdungen, denen der Mensch in seiner Personenwürde angesichts der modernen Welt ausgesetzt ist. Papst Johannes Paul II. kritisierte besonders jene Tendenzen, die das Recht des Menschen auf Leben und Würde in seiner Existenz als Person untergraben: die Glaubenskrise, einen sittlichen Relativismus und Subjektivismus, die Faszination für erdachte Werte und die damit einhergehende Entwertung geistlicher Werte sowie das Empfinden, Leben und Welt seien absurd ${ }^{2}$. Mit großer Besorgnis wurde der Heilige Vater nicht müde, die Bedeutung der personalen Würde jedes einzelnen Menschen zu unterstreichen, ohne die eine humane Welt weder geschaffen noch fortbestehen kann. Keimzelle der Gesellschaft ist die Familie, wo der Mensch in sein personales und soziales Leben eingeführt wird. Deshalb wird in dem vorliegenden Artikel erläutert, welchen zentralen Stellenwert die Betrachtung des Menschen als Person für Papst Johannes Paul II. in seinem Bild von der Familie einnimmt. Zunächst wird die Familie als Gemeinschaft von Personen vorgestellt, bevor auf die Person selbst eingegangen wird, die den Bezugspunkt für die Familienpädagogik und die Familienerziehung ausmacht.

\section{Die Familie als communio personarum}

Gott selbst ist die Quelle des Ehebundes und der Familie, denn sie ist als Gemeinschaft des Lebens und der Liebe zwischen autonomen Personen, als communio personarum eingesetzt. Damit verweist sie auf das große Geheimnis der Liebe Gottes und auf das Mysterium der Dreifaltigkeit. In der ehelichen Verbindung von Mann und Frau spiegelt sich der Bund Gottes mit den Menschen wider, die Liebe zwischen Mann und Frau zeugt von der Liebe Gottes zu den Menschen. Gott hat den Menschen nach seinem Abbild erschaffen, damit er als

\footnotetext{
${ }^{1}$ Vgl. S. Swieżawski, Karol Wojtyła w Katolickim Uniwersytecie Lubelskim, in: S. Swieżawski, Istnienie i tajemnica, Lublin 1993, S. 333-334.

${ }^{2}$ Vgl. Reconciliatio et paenitentia 18; K. Gryz (Hrsg.), Człowiek droga Kościoła. Moralne aspekty nauczania Jana Pawła II, Kraków 2004; L. Dyczewski (Hrsg.), Człowiek w społeczności. Refleksje nad społecznym nauczaniem Jana Pawła II, Niepokalanów 1988; S. Chrobak, Koncepcja wychowania personalistycznego w nauczaniu Karola Wojtyly - Jana Pawła II, Warszawa 1999; W. Czamara, Przemiana religijno-moralna człowieka w nauczaniu Jana Pawła II, Poznań 1997; J. Czarny, Jana Pawła II wizja cywilizacji miłości, Wrocław 1994; J. Majka, Doskonalenie człowieka, „Nowe Życie” 2 (1984) Nr 8, S. 5; L. Bilicki, Świat oczekuje na cywilizację miłości, in: Wierze w Boga Ojca. Program duszpasterski na rok 1998/1999, Katowice 1998, S. 270.
} 
freies Individuum mit personaler Würde leben kann. Als Mann und Frau kann der Mensch den Ehebund eingehen und damit zum Mitarbeiter am göttlichen Schöpfungsplan werden. Durch die Ehe will Gott selbst seinen Liebesplan in der Menschheit verwirklichen, denn er beschenkt die Ehegatten mit der Fähigkeit, das Leben an ihre Kinder weiter zu geben. Die Vereinigung zweier Menschen ist von Gott so erdacht, dass sie zum Abbild Gottes wie auch zur Quelle neuen Lebens wird ${ }^{3}$.

Die Liebe führt die beiden Ehegatten auf innige Weise zur Gemeinschaft und findet ihre Krönung im gemeinsamen Kind. Das Beschenken mit Leben wird zum sichtbaren Zeichen, dass die Liebe zwischen zwei Personen einen neuen Menschen entstehen lässt und damit zur Liebe zwischen drei Personen wird. So wie aus der Liebe des Vaters zum Sohn und aus der Liebe des Sohnes zum Vater auf ewig eine neue Person entsteht - der Heilige Geist, kommt in ähnlicher Weise aus der Liebe des Mannes und der Frau ein Kind zur Welt, das durch seine eigene spezifische Art zu einem neuen Band wird, das die Eltern verbindet ${ }^{4}$. Die eheliche Liebe ist ein Geschenk Gottes - des Vaters. Verurteilt durch die Erbsünde wurde sie durch Christus gereinigt und geheiligt, kraft des Heiligen Geistes ist sie dazu eingesetzt und konsekriert, die Kirche und die menschliche Gemeinschaft in Liebe und Frieden aufzubauen 5 . Die Familie wird so zu einer Gemeinschaft von Personen, zu einer communio personarum, die ihr Zusammenleben in der

${ }^{3}$ Vgl. J. Bajda, Powołanie małżeństwa i rodziny, in: K. Majdański (Hrsg.), Teologia matżeństwa i rodziny, T. 1, Warszawa 1980, S. 51; J. Bajda, Rodzina miejscem Boga i człowieka, Łomianki 2005; J. Stala, Familienkatechese in Polen um die Jahrhundertwende. Probleme und Herausforderungen, Tarnów 2008; K. Lubowicki, Duchowość matżeńska w nauczaniu Jana Pawła II, Kraków 2005; J. Stala, E. Osewska (Hrsg.), Rodzina - bezcenny dar i zadanie, Radom 2006; M. Ozorowski, W. Nowacki (Hrsg.), Rodzina droga Kościoła, Łomża 2005; M. Drożdż (Hrsg.), Człowiek między losem a wyborem, Tarnów 2006; W. Muszyński, E. Sikora (Hrsg.), Matżeństwo i rodzina w ponowoczesności. Szanse-zagrożenia-patologie, Toruń 2008; K. Gryz (Hrsg.), Człowiek droga Kościoła, Kraków 2004; A. Offmański (Hrsg.), Małżeństwo i rodzina w panoramie współczesnych systemów, Szczecin 2006; B. Mierzwiński, E. Dobowska (Hrsg.), Oblicze współczesnej rodziny polskiej, Kraków 2003; M. Ryś, M. Jankowska (Hrsg.), W trosce o rodzine, Warszawa 2007; J. Stala, Własny i oryginalny charakter wychowania $w$ rodzinie, in: J. Bednarczyk (Hrsg.), Historia vita memoriae. Prace dedykowane ks. profesorowi Stanisławowi Piechowi, Kraków 2008.

${ }^{4}$ Vgl. C. Murawski, Teologia matżeństwa i rodziny w nauczaniu biskupów polskich 19451980, Sandomierz 1988, S. 121.

5 Vgl. D. Luber, Koncepcja więzi matżeńskiej Jana Pawła II inspiracja prorodzinnego wychowania dzieci i młodzieży, in: B. Muchacka (Hrsg.), Rodzina w kontekście współczesnych problemów wychowania, Kraków 2008, S. 67-77; A. Adamiec-Zgraja, Fenomen rodzicielstwa człowieka przełomu wieków. Szansa czy zagrożenie dla rodziny?, in: B. Muchacka (Hrsg.), Rodzina w kontekście współczesnych problemów wychowania, Kraków 2008, S. 155-164; J. Bajda, Teologia mitości matżeńskiej, „Ateneum Kapłańskie” 67 (1975) Nr 397, S. 175-186. 
Gemeinsamkeit gestaltet. Jedes Familienmitglied ist als individuelle Person geschaffen, die ihre vollkommene Menschlichkeit erst in der Beziehung zu anderen Personen verwirklichen kann. Auch hier kann der exemplarische Bezug zum göttlichen „Wir” hergestellt werden, denn nur Personen sind dazu imstande, in der Gemeinsamkeit zu leben ${ }^{6}$.

Deshalb müssen die christlichen Ehegatten, gestärkt durch das Sakrament, von Anfang an ihre Herzen und Gedanken jenem Gott zuwenden, von dem jede Elternschaft ausgeht, damit ihre menschliche Elternschaft jedes Mal aus dieser Quelle die Kraft zur unablässigen Erneuerung der Liebe schöpfe und zur Stärkung der Gemeinsamkeit der Personen beitrage?. Die Familie soll mit aller Kraft an ihrem großen und bedeutenden Auftrag arbeiten, im Zusammenleben wahre Gemeinschaft $\mathrm{zu}$ verwirklichen und dadurch $\mathrm{zu}$ einer wahrhaften communio personarum zu werden. „Die innere Grundlage, die ständige Kraft und das letzte Ziel dieser Aufgabe ist die Liebe" ${ }^{8}$. Die Liebe zwischen allen Familienmitgliedern führt zu einer immer innigeren und stärkeren Gemeinschaft. Sie gründet auf der Gemeinsamkeit der Ehegatten, die kraft ihres ehelichen Liebesbundes - „nicht mehr zwei, sondern eins" - dazu berufen sind, in ihrer Einheit ständig zu wachsen durch die Treue, mit der sie täglich zu ihrem Eheversprechen gegenseitiger Ganzhingabe stehen'. Diese Gemeinsamkeit wird zur Grundlage, auf der die Gemeinschaft der Liebe entsteht, in der alle Mitglieder der Familie verbunden sind. Die Liebe zwischen Mann und Frau in der Ehe und, in abgeleiteter und erweiterter Form, die Liebe zwischen den Mitgliedern der gleichen Familie ist von einer inneren und bleibenden Dynamik beseelt und getragen, welche die Familie zu einer immer tieferen und intensiveren Einheit führt, der Grundlage und Seele für die Ehe- und Familien-Gemeinschaft ${ }^{10}$.

${ }^{6}$ Por. Gratissimum sane 7; J. Stala, Matżeńsko-rodzinna communio personarum jako punkt odniesienia integralnie rozumianej miłości, „Roczniki Teologiczne” 54 (2007), T. 8, S. 141-152.

${ }^{7}$ Vgl. Gratissimum sane 7.

${ }^{8}$ Familiaris consortio 18.

${ }^{9}$ Vgl. Familiaris consortio 19.

${ }^{10}$ Por. Familiaris consortio 18; Gratissimum sane 7-8; Jan Paweł II, Mężczyzna i niewiasta stworzyt ich, Watykan 1986, S. 39; E. Ozorowski (Hrsg.), Stownik matzeństwa i rodziny, Warszawa-Lomianki 1999, S. 198-199; K. Wojtyła, Rodzina jako communio personarum, „Ateneum kapłańskie” 66 (1974) Nr 83, S. 347-361; J. Bajda, Powołanie małżeństwa i rodziny, in: K. Majdański (Hrsg.), Teologia matżeństwa i rodziny, Warszawa 1980, S. 103; J. Grześkowiak, Matżeństwo jako analogia trynitarna, „Roczniki Teologiczno-Kanoniczne” 29 (1982) T. 6, S. 4154; J. Laskowski, Matżeństwo wspólnota miłości, Warszawa 1993, S. 128; J. Laskowski, Trwałość wspólnoty matżeńskiej, Warszawa 1987, S. 183; J. Buxakowski, Wprowadzenie do teologii duszpasterstwa rodzin, Pelplin 1999, S. 26; P. Petryk, Ku wspólnocie życia i miłości, Lublin 1998, S. 193-203. 
Durch das Erfahren und das tägliche aktive Verwirklichen der Lebens- und Liebesgemeinschaft wird die Familie zu einer wahrhaften Hauskirche ${ }^{11}$. Als Hauskirche ist sie ein wesentlicher Baustein der allgemeinen Kirche, da „eine spezifische Darstellung und Verwirklichung dieser kirchlichen Gemeinschaft die christliche Familie ist"12. Durch das Beispiel gelebter christlicher Gemeinschaft kann die Familie auf die Kirche und die gesamte Gesellschaft ausstrahlen ${ }^{13}$.

Die Familie ist der Weg der Kirche in die Zukunft. Durch die Einbindung der Familie in die Heilssendung der Kirche eröffnet sich eine Chance, die Mission der Kirche in einer Welt aussichtsreich zu realisieren ${ }^{14}$, wo es immer schwieriger wird, über Gott zu sprechen. Die Familie - eine Gemeinschaft von Personen nimmt auf ganz natürliche Art und Weise am alltäglichen Leben beinahe jedes Menschen Anteil und kennt dessen Bedürfnisse und Probleme, somit kann sie diese Mission am besten erfüllen. Die christlichen Familien können zu einem Zeichen der Liebe werden ${ }^{15}$. Im Bewusstsein der Wahrheit, eine Hauskirche zu sein, öffnet sich die Familie der gesamten Menschheit, um dieser zeichenhaft ihre Rolle im Heilsplan Gottes für die Welt zu offenbaren, der mit Hilfe der Familie die ganze Menschheit zu Christus hinführen will ${ }^{16}$. Ihr bedeutendster Beitrag in der Menschheitsgeschichte und gleichzeitig ein Ausdruck ihrer Offenheit gegenüber der Menschheit besteht in der Vertiefung ihrer Erfahrung als Gemeinschaft von Personen, die das Alltagsleben der Familien durch das Gesetz des unentgeltlichen Schenkens und einer tiefgründigen Solidarität prägen soll ${ }^{17}$. Die Familie stellt den ursprünglichen Ort und das wirksamste Mittel dafür dar, die Menschheit vollkommener zu machen, indem sie das Leben auf der Welt zunehmend humaner gestaltet ${ }^{18}$. Gestützt auf ihre reale Anteilnahme am Heilswirken Gottes ist die Familie bereits aus ihrer Natur heraus zum Aufbau und zur Vertiefung der Zivilisation der Liebe in dieser Welt begabt. Die Familie entfaltet auch heute noch beträchtliche Energien, die imstande sind,

${ }^{11}$ Vgl. Lumen gentium 11.

${ }^{12}$ Familiaris consortio 21

${ }^{13}$ Vgl. Familiaris consortio 43; S.M. Kałdon, Rodzina Kościołem domowym przez wzajemna miłość $i$ wspólnotę życia, in: J. Kupny, M. Łuczak (Hrsg.), Testament społeczny Jana Pawła II, Katowice 2006, S. 68-90.

${ }^{14}$ Vgl. J. Tarnowski, Katecheza w rodzinie: obawy i nadzieje, „Katecheta” 25 (1981) Nr 6, S. 255.

${ }^{15}$ Vgl. G. Hibon, Zaangażowanie matżeńskie, in: XVIII Międzynarodowy Kongres Rodziny, Warszawa 1994, S. 441.

${ }^{16}$ Vgl. Familiaris consortio 49.

${ }^{17} \mathrm{Vgl}$. Familiaris consortio 43.

${ }^{18} \mathrm{Vgl}$. Gaudium et spes 52. 


\section{6

den Menschen seiner Anonymität zu entreißen, in ihm das Bewusstsein seiner Personwürde wach zu halten, seine tiefe Menschlichkeit zu entfalten und ihn als aktives Mitglied in seiner Einmaligkeit und Unwiederholbarkeit der Gesellschaft einzugliedern ${ }^{19}$.

Das Zusammenleben als Personen in der Familiengemeinschaft soll nicht isoliert bleiben. Die familiäre communio personarum öffnet sich vielmehr der Gesellschaft und verfügt damit über eine weitreichendere Dimension, welche alle Menschen betrifft. Die Öffnung der Familie - als wirkliche Gemeinschaft - auf die gesamte Menschheit hin ist das bedeutendste Element des Zeugnisses, das sie ablegen kann. Diese Öffnung verwirklicht sich am umfassendsten darin, dass alle Familienmitglieder zur vollen persönlichen, zur menschlichen und christlichen Reife geführt werden ${ }^{20}$. Angesichts einer Gesellschaft, die in Gefahr ist, den Menschen immer mehr seiner personalen Einmaligkeit zu berauben und zur „Masse” zu machen und so selbst unmenschlich und menschenfeindlich zu werden, setzt die moderne Welt ihre stets wachsende Hoffnung auf den Dialog zwischen der einzelnen Familie mit anderen Familien wie auch mit der Kirche und der Welt ${ }^{21}$. Ohne einen derartigen Dialog sind weder eine gut funktionierende Familiengemeinschaft noch als Konsequenz daraus ein wirksames Laienapostolat vorstellbar $^{22}$. Die besondere Dynamik der Einflussnahme, wie sie sich in der Familie vollzieht, ergibt sich aus der Gesamtheit der wechselseitigen Beziehungen, der Grundhaltungen, des Einwirkens und des Verhaltens, welche sich auf die Persönlichkeitsentwicklung der Kinder auswirken, ihre Bedürfnisse befriedigen, sie bei der Gestaltung eines bestimmten Systems von Werten und Normen sowie ihrer Weltanschauung unterstützen ${ }^{23}$.

19 Vgl. Familiaris consortio 43; L. Bakiera, Wartość matżeństwa $w$ rozwoju człowieka dorosłego, in: B. Harwas-Napierała (Hrsg.), Rodzina jako wartość w rozwoju człowieka, Poznań 2009, S. 25-57; A. Ryk, Wspótczesna rodzina wobec wybranych problemów ponowoczesności, in: B. Muchacka (Hrsg.), Rodzina w kontekście współczesnych problemów wychowania, Kraków 2008, s. 33-40; E. Jakubowska, A. Sobocin, Rodzina - bezcenny dar, in: B. Muchacka (Hrsg.), Rodzina $w$ kontekście wspótczesnych problemów wychowania, Kraków 2008, S. 87-93; D. Pauluk, Role rodzinne kobiety wobec wyzwań wspótczesności, in: B. Muchacka (Hrsg.), Rodzina w kontekście współczesnych problemów wychowania, Kraków 2008, S. 95-104.

${ }^{20}$ Vgl. Familiaris consortio 2.

${ }^{21} \mathrm{Vgl}$. Familiaris consortio 43.

${ }^{22}$ Vgl. J. Tarnowski, Dynamizm pedagogiczny adhortacji apostolskiej „Familiaris consortio”, „Katecheta” 26 (1982) Nr 4, S. 153.

${ }^{23}$ Vgl. A. Przybysz, Preferowany model rodziny w opinii studentek krakowskich uczelni, in: B. Muchacka (Hrsg.), Rodzina w kontekście współczesnych problemów wychowania, Kraków 2008, S. 105-115; A. Świątek, Rola seniorów w rodzinie i społeczeństwie z perspektywy filozofii $i$ psychologii, in: B. Muchacka (Hrsg.), Rodzina $w$ kontekście wspótczesnych problemów wychowania, Kraków 2008, S. 129-139; J. Daszykowska, Wartość rodziny w życiu nauczycieli 
Die Existenz der Familie als Ort für ein besonderes Lebenszeugnis zielt auf das Streben nach persönlicher Heiligkeit ebenso ab wie auf die Teilnahme am Aufbau einer christlichen Welt. Bereits seit urgeschichtlicher Zeit wurde die Familie als Garant des Glaubens und des großen sittlichen und kulturellen Erbes betrachtet. Sie war Garant für die Bindungen, die Einheit, die Zukunft, die Verbindlichkeit und die Gesundheit der Gesellschaft. In ihrem Schoß realisierte sich jene unwiederholbare Verbindung sowohl des moralischen wie auch des materiellen Erbes. Die Familie verlieh der Geschichte ihren Sinn. Sie gab Wurzeln und Bezugspunkte, Kraft und Ziel zum Voranschreiten, Kraft und Anlass dafür, sich selbst zu retten indem sie gerettet wurde. Als Liebes- und Lebensgemeinschaft stellt die Familie eine besonders stark gefestigte und auf ihre eigene Art und Weise souveräne Gesellschaft im Kleinen dar, obwohl sie in vielfältigen Abhängigkeiten besteht. Darum verweisen die Rechte der Familie auf ihre besondere Nähe zu den allgemeinen Menschenrechten. Wenn die Familie eine Gemeinschaft von Personen ist, hängt ihre Selbstverwirklichung in hohem Maß davon ab, ob die Rechte jeder Einzelperson geachtet werden, durch die sie erst zur Familie wird. Gleichzeitig ist die Familie jedoch viel mehr als jede einzelne menschliche Person für sich. Alle großen Gesellschaftsformen (Volk, Staat, Kirche) sind zumindest mittelbar von der Existenz und der Funktionalität der Familie abhängig. Jegliches weitere Verschieben des Plans für eine derartig besondere Gemeinschaft - wie sie die Familie ist - kann nur die Zerstörung ihrer authentischen sozialen Subjektivität bedeuten ${ }^{24}$.

studiujacych, in: B. Muchacka (Hrsg.), Rodzina w kontekście wspótczesnych problemów wychowania, Kraków 2008, S. 141-153; B. Muchacka, Rola rodziny i szkoły w przezwyciężaniu kryzysów rozwojowych przez dzieci, in: B. Muchacka (Hrsg.), Rodzina w kontekście współczesnych problemów wychowania, Kraków 2008, S. 177-186; S. Cudak, Konflikty rodzinne a trudności wychowawcze dzieci i młodzieży, in: B. Muchacka (Hrsg.), Rodzina w kontekście wspótczesnych problemów wychowania, Kraków 2008, S. 197-206; J.A. Wnęk, Obawy zwiazane z petnieniem roli rodzica $w$ opinii studentów, in: B. Muchacka (Hrsg.), Rodzina w kontekście współczesnych problemów wychowania, Kraków 2008, s. 221-230.

24 Vgl. Gratissimum sane 17; I. Czaja-Chudyba, Rodzina przestrzenia wspierania lub ograniczania twórczej i krytycznej postawy dziecka, in: B. Muchacka (Hrsg.), Rodzina w kontekście wspótczesnych problemów wychowania, Kraków 2008, S. 285-298; D. Morańska, Wptyw środowiska rodzinnego na ksztaltowanie się postaw dzieci $i$ młodzieży obywateli społeczeństwa informacyjnego, in: B. Muchacka (Hrsg.), Rodzina w kontekście współczesnych problemów wychowania, Kraków 2008, S. 401-410; G. Paprotna, Trudności współczesnej rodziny w procesie wychowania dzieci, in: B. Muchacka (Hrsg.), Rodzina w kontekście wspótczesnych problemów wychowania, Kraków 2008, S. 411-418; B. Oelszlaeger, Rodzinne więzy we wspótpracy międzynarodowej, in: W. Korzeniowska, A. Murzyn, H. Lukasova-Kantorkova (Hrsg.), Rodzina dla Europy czy Europa dla rodziny?, Kraków 2006, S. 39-45; J. Mazur, Prawne możliwości ochrony rodzin $w$ Polsce, in: W. Korzeniowska, A. Murzyn, H. Lukasova-Kantorkova (Hrsg.), Rodzina dla Europy czy Europa dla rodziny?, Kraków 2006, S. 47-62. 


\section{Die Person als Bezugspunkt für die Familienpädagogik und die Familienerziehung}

Papst Johannes Paul II. rückte Identität und Sendung der Familie in das Zentrum einer Vielzahl von Schreiben und Reflexionen. Seiner Meinung nach liegen die großen Aufgaben der Familie in der Erfüllung folgender Ziele: die Entwicklung und Vertiefung des persönlichen Bundes mit Gott, die Aufrechterhaltung und Erfüllung des Ehebundes sowie das beständige Bemühen alles zu unternehmen, was dem Wohl und der Entfaltung des Kindes dient. Wenn die Familie diese ihre besonderen Aufgaben annimmt und sie zu verwirklichen sucht, dann erfüllt sie ihre grundlegende Mission: Sie hütet, offenbart und teilt die Liebe mit. Nach dem göttlichen Heilsplan wird der neue Mensch aus Liebe geboren und seiner Familie anvertraut, die nun die Verantwortung für seine Zukunft trägt. In der Familie soll sich tagtäglich bestätigen, dass sie tatsächlich das Lebensumfeld seines irdischen Glücks und seiner menschlichen Hoffnung darstellt. Wenn die Eltern aus Liebe und für die Liebe einer neuen Person das Leben schenken, die um ihrer selbst willen dazu berufen ist, heranzuwachsen und sich weiter zu entwickeln, dann nehmen sie damit auch die Aufgabe an, diesem Kind ein in seiner Gänze humanes Leben zu ermöglichen ${ }^{25}$. Die Familie ist die einzige Gemeinschaft, in der jeder Mensch um seiner selbst willen geliebt ist. Denn der Grundsatz für die eheliche Gemeinschaft besteht eben nicht im Streben nach dem eigenen Nutzen und der eigenen Annehmlichkeit ${ }^{26}$, vielmehr steht das Wohlergehen des geliebten Partners im Mittelpunkt des Denkens und Handelns. Die auf gegenseitiger Liebe gegründete christliche Familie bejaht jedes Mitglied als Person, die über ihre eigene Würde und Subjektivität verfügt und bedingungslos gewollt und angenommen wird. Als Gemeinschaft von Personen konzentriert sie die Ausgestaltung ihres Zusammenlebens auf den Menschen: auf diesen konkreten, immer einzigartigen und unwiederholbaren Menschen, der ihr von Gott anvertraut ist. Die Familie ist die Wiege des Lebens und der Liebe, wo der Mensch geboren wird und sicher

${ }^{25}$ Vgl. J. Stala, Die Transzendenz als bestimmendes Merkmal der Person in der Anthropologie und der Pädagogik Johannes Pauls II., „The Person and the Challenges” 2 (2012) Nr 1, S. 61-75; S. Pyszka, Godność osoby ludzkiej jako podstawa nauczania społecznego Jana Pawła II, in: J. Kupny, M. Łuczak (Hrsg.), Testament społeczny Jana Pawta II, Katowice 2006, S. 11-36.

${ }^{26}$ Vgl. U. Gruca-Miąsik (Hrsg.), Dziecko i rodzina. Społeczne powinności opieki i wychowania, Rzeszów 2007; J. Żukowicz (Hrsg.), Dziecko w nauczaniu Jana Pawła II, Kraków 1985; S. Cader, Rodzina środowiskiem wychowawczym w świetle nauczania Jana Pawła II, Kraków 2004; S. Szczerek, Postuga rodzinie w nauczaniu Jana Pawła II, Sandomierz 2006; D. Luber, Koncepcja więzi matżeńskiej Jana Pawła II inspiracja prorodzinnego wychowania dzieci i młodzieży, in: B. Muchacka (Hrsg.), Rodzina w kontekście współczesnych problemów wychowania, Kraków 2008, S. 67-77. 
heranwächst ${ }^{27}$. Nach dem Plan Gottes für diese Welt sind die Eltern Mitarbeiter an der Schöpfung, denn sie geben das Leben an die nächste Generation weiter. Ihre Verantwortung beginnt mit der Zeugung und der Geburt des neuen Lebens und erstreckt sich im Folgenden auf den gesamten Erziehungsprozess. Das Kind soll sich in seiner persönlichen und sozialen Dimension ganzheitlich entfalten können, damit es zu einem reifen und verantwortungsbewussten Mitglied von Familie, Kirche und Gesellschaft werden kann. Dabei sind es insbesondere die Eltern, die dem Kind alles zusichern müssen, was dieses für sein Heranwachsen und seine Entwicklung benötigt ${ }^{28}$. Die Familie ist der einzige Ort, wo der Mensch um seiner selbst willen geliebt wird, denn die Ehe basiert nicht auf Utilitarismus und Eigennutz. Deshalb soll das Umfeld, in dem der Mensch heranwächst, die Wiege des Lebens und der Liebe, des Glücks und der Hoffnung sein ${ }^{29}$.

Johannes Paul II. war der festen Überzeugung, dass die Familie als die erste und bedeutendste soziale Gemeinschaft zu betrachten sei, in die der Mensch hineingeboren wird. Alle anderen gesellschaftlichen Institutionen, auch der Staat und die Kirche, basieren auf dieser grundlegenden Gemeinschaft und hängen von ihr ab. In der Familie sind es die Eltern, welche die Hauptverantwortung für die Erziehung ihrer Kinder tragen. Da sie ihren Kindern das Leben schenkten, müssen sie auch deren erste und bevorzugte Erzieher sein. Diese Aufgabe ist das naturgegebene Recht der Eltern, beinhaltet jedoch gleichzeitig auch die Verpflichtung zur Übernahme dieser verantwortungsvollen Bestimmung. Im Vergleich mit den Erziehungsaufgaben anderer gesellschaftlicher Institutionen und Einrichtungen muss der Erziehungsauftrag der Eltern als ursprünglich angesehen werden ${ }^{30}$. Für den Heiligen Vater ist die erzieherische Berufung der Familie, insbesondere die der Eltern, von so großem Gewicht, dass sie seiner Meinung nach dort, wo sie eventuell fehlt, nur unter Schwierigkeiten zu ersetzen ist ${ }^{31}$. Die christlichen Eltern verstehen ihre Erziehungsmission sogar als

${ }^{27}$ Vgl. M. Łopatkowa, Rodzina w globalnym świecie, in: W. Korzeniowska, A. Murzyn, U. Szuścik (Hrsg.), Rodzina -w świetle zagrożeń realizacji dotychczasowych funkcji. Szkice monograficzne, Katowice 2007, S. 126-133; B. Dymara, Przestrzenie interpersonalne pomiędzy rodzina a szkoła, in: W. Korzeniowska, A. Murzyn, U. Szuścik (Hrsg.), Rodzina - w świetle zagrożeń realizacji dotychczasowych funkcji. Szkice monograficzne, Katowice 2007, S. 134-144.

${ }^{28}$ Vgl. Familiaris consortio 17, 22; S. Chrobak, Koncepcja wychowania personalistycznego w nauczaniu Karola Wojtyty - Jana Pawta II, Warszawa 1999, S. 86-89.

${ }^{29}$ Vgl. A. Rynio, Integralne wychowanie w myśli Jana Pawła II, Lublin 2004, S. 236-237.

${ }^{30}$ Vgl. Gratissimum sane 7; Familiaris consortio 36.

${ }^{31}$ Vgl. Gravissimum educationis 3; Gaudium et spes 50; A. Grześkowiak, Prawa rodziny $w$ świetle międzynarodowych aktów praw człowieka, in: A. Liskowacka, E. Szczotok (Hrsg.), Ewangelizacja wspólnoty matżeńskiej i rodzinnej, Katowice 1993, S. 223-224. 
Berufung, die dem Sakrament der Taufe und dem Sakrament der Ehe entspringt ${ }^{32}$. Als bekennende Christen übernehmen sie die Aufgabe, den Glauben und die Liebe an ihre Kinder weiter zu geben und dabei selbst im Glauben und in der Liebe zu wachsen. Sie können jedoch darauf vertrauen, dass Gott ihnen nicht nur dieses Privileg und die Pflicht zur Erziehung ihrer Nachkommen übertragen hat. Vielmehr sichert er den christlichen Ehegatten durch die empfangenen Sakramente auch die Gnade zu, diese ihre überaus bedeutende Mission und Sendung verantwortungsvoll erfüllen zu können ${ }^{33}$.

In der ehelichen Gemeinschaft und in der Familie leben Menschen als eigenständige Personen zusammen. Insbesondere in der Familie begegnen sich die unterschiedlichen Generationen, um gemeinsam eine wahre communio personarum zu gestalten. Zwischen den einzelnen subjektiven Mitgliedern der Familie bilden sich vielfältige interpersonale Beziehungen heraus - die bräutliche, die väterliche und mütterliche, die kindliche, die geschwisterliche ${ }^{34}$. Alle entstandenen Beziehungen tragen wesentliche Merkmale in sich und leisten einen unverzichtbaren Beitrag für ein gelungenes Zusammenleben, bei dem Subjektivität und Würde jeder einzelnen Person geachtet werden. Papst Johannes Paul II. betonte jedoch ausdrücklich, dass dennoch die väterliche und mütterliche Liebe das wichtigste Element im erzieherischen Handeln der Familie darstellt. Sie ist der bestimmende Faktor und legt die Norm jeglichen erzieherischen Einwirkens fest. Denn das Kind stellt eine untrennbare Synthese von Vaterschaft und Mutterschaft dar ${ }^{35}$. Erst durch die Vereinigung von Mann und Frau in der

${ }^{32}$ Vgl. Familiaris consortio 13; Katechismus der Katholischen Kirche 1213, 1254, 1269.

${ }^{33}$ Por. Gratissimum sane 16; Gravissimum educationis 3; Jan Pawet II o matżeństwie i rodzinie, Warszawa 1982, S. 175-179; J. Wilk, Pedagogika rodziny. Zagadnienia wybrane, Lublin 2002, S. 13-35; M. Filipiak, Biblia o człowieku, Lublin 1979, S. 274; K. Romaniuk, Być dzieckiem wedtug Biblii, „Communio” 3 (1985), S. 3-17; J. Szlaga, Biblijne i teologiczne aspekty biblijnego spojrzenia na dziecko, „Zeszyty Naukowe KUL” 3 (1980), S. 51-61; J. Lach, Biblijne określenia dziecka i ich symbolika, in: W. Piwowarski, W. Zdaniewicz (Hrsg.), Dziecko, Warszawa-Poznań 1984, S. 5-20; M. Filipiak, Biblijne podstawy teologii matżeństwa i rodziny w Starym Testamencie, Lublin 1984, S. 87; J. Wilk, Problem współczesnego katechumenatu rodzinnego, Lublin 1976, S. 68-69; S. Longosz, Rodzina wczesnochrześcijańska i jej zadania w nauczaniu św. Bazylego Wielkiego, „Roczniki Teologiczno-Kanoniczne” 4 (1981), S. 150; J. Bajda, Problem dziecka w teologii, in: W. Piwowarski, W. Zdaniewicz (Hrsg.), Dziecko, Warszawa-Poznań 1984, S. 39-50; F. Adamski, Socjologia matżeństwa i rodziny, Warszawa 1984, S. 123-125; J. Ozdowski, Rola rodziny w wychowaniu młodzieży, „Zeszyty Naukowe KUL” 3 (1969), S. 29-41.

${ }^{34} \mathrm{Vgl}$. Familiaris consortio 15.

${ }^{35}$ Vgl. U. Gruca-Miąsik(Hrsg.), Dziecko i rodzina. Społeczne powinności opieki i wychowania, Rzeszów 2007; J. Żukowicz (Hrsg.), Dziecko w nauczaniu Jana Pawła II, Kraków 1985; V. Satir, Rodzina. Tu powstaje człowiek, Gdańsk 2000. 
Liebe wird das Leben weiter geschenkt. Die beiden Ehegatten werden mit dem Geschenk des Kindes zu Eltern und nehmen damit eine neuartige und besondere Verantwortung an. Sie sind nicht mehr nur sich selbst und dem Ehepartner verantwortlich sondern stellen sich bewusst ihrer neuen Rolle als Eltern eines fürsorgebedürftigen Kindes. Ihre elterliche Liebe soll für ihre Kinder zum sichtbaren Zeichen der Liebe Gottes werden, von der jede Vaterschaft im Himmel und auf Erden ihren Namen hat ${ }^{36}$.

Gott selbst hat einer Frau, der Heiligen Jungfrau Maria, seinen eigenen Sohn anvertraut. Maria ist dadurch zur Mutter des Gottessohnes und gleichermaßen zur Mutter der Kirche geworden. Darin lässt sich die besondere Bedeutung der Mutterschaft ablesen: Die Mutter ist Herz und Mittelpunkt der Familiengemeinschaft. Bereits in der vorgeburtlichen Phase baut sie nicht nur den Organismus des Kindes sondern indirekt seine ganze Menschlichkeit auf. An den zentralen Punkten des kindlichen Lebens, bei der Geburt, beim Stillen und bei der Erziehung, kann niemand die Mutter ersetzen. Ebenso kann niemand und nichts das mütterliche Herz im familiären Heim ersetzen, ein Herz, das immer da ist und immer dort wartet. Auch wenn moderne Tendenzen in der Politik diese Tatsache zu negieren suchen, bleibt die Mutter vor allem in den ersten Lebensjahren des Kindes der fundamentale Bezugspunkt, der in allen Situationen Sicherheit und Liebe ausstrahlt. Wenn das heranwachsende Kind selbstständig erste Schritte in den Kindergarten, die Schule, an den Ausbildungsplatz oder in eine eigene Wohnung unternimmt, wird die Mutter stets eine zuverlässige Begleitung, einen sicheren Halt und einen konstanten Bezugspunkt bieten. Die Mutter trägt den Reichtum ihrer Empfindsamkeit, ihrer Intuition, ihrer Aufopferung und ihrer Beständigkeit in das familiäre Heim und folglich auch in das gesamte gesellschaftliche Leben hinein ${ }^{37}$.

Wenn auch die Mutter nach Meinung des Heiligen Vaters eine unersetzbare und zentrale Rolle im Erziehungsprozess einnimmt, sind die Bedeutung und die Aufgaben des Vaters von ebenso großen Gewicht. Da der Mann an der Zeugung des neuen menschlichen Lebens wesentlich beteiligt ist,

${ }^{36}$ Vgl. Familiaris consortio 14; Humane vitae 9; A. Adamiec-Zgraja, Fenomen rodzicielstwa człowieka przełomu wieków. Szansa czy zagrożenie dla rodziny?, in: B. Muchacka (Hrsg.), Rodzina w kontekście wspótczesnych problemów wychowania, Kraków 2008, S. 155-164.

${ }^{37}$ Vgl. Familiaris consortio 22; A. Sorkowicz, Geniusz kobiety - kilka słów o feminizmie Jana Pawła II, in: W. Korzeniowska, A. Murzyn, U. Szuścik (Hrsg.), Rodzina - w świetle zagrożeń realizacji dotychczasowych funkcji. Szkice monograficzne, Katowice 2007, S. 18-26; D. Pauluk, Role rodzinne kobiety wobec wyzwań współczesności, in: B. Muchacka (Hrsg.), Rodzina w kontekście wspótczesnych problemów wychowania, Kraków 2008, S. 95-104; A. Przybysz, Preferowany model rodziny w opinii studentek krakowskich uczelni, in: B. Muchacka (Hrsg.), Rodzina w kontekście wspótczesnych problemów wychowania, Kraków 2008, S. 105-115. 
stehen Vaterschaft und Mutterschaft in enger und untrennbarer Verbindung zueinander. Der Vater trägt somit die volle Verantwortung für das im Schoß der Mutter empfangene junge Leben. Eine verantwortliche Elternschaft kann nur aus dem Zusammenwirken von verantwortlicher Vater- und Mutterschaft entstehen. Erst in der gemeinschaftlichen Übernahme der elterlichen Rechte und Pflichten zeigen sich Reife und Würde der beiden Ehegatten. Eine bewusst wahrgenommene Vaterschaft, die für das im Schoß der Frau empfangene und dann in die Welt gegebene Leben Verantwortung übernimmt, findet ihre Fortsetzung im Erziehungsprozess ${ }^{38}$. Gerade in der modernen Zeit wird der positive Einfluss des Vaters auf einen erfolgreichen Erziehungsprozess des Kindes wieder verstärkt wahrgenommen. Väter werden ermutigt und dazu aufgerufen, sich ihrer Rolle aktiv und selbstbewusst zu stellen, da besonders in der kritischen Phase der ausgehenden Kindheit und der Pubertät das gezielte und liebevolle Einwirken des Vaters überaus hilfreich sein kann. Dabei sollen Vater und Mutter die Grundlinien der Erziehung gemeinschaftlich festlegen und klare Absprachen treffen. Als Mitarbeiter am göttlichen Schöpfungsplan erfüllt der Vater seine Berufung umfassend, wenn er seine Aufgaben in der Ehe und der Familie annimmt und ernsthaft zu realisieren sucht. Die Liebe zu seiner Frau und seinen Kindern bildet dafür eine sichere Basis und steht an erster Stelle. Wie der Heilige Vater ausdrücklich unterstreicht, ist der Mann im Namen dieser Liebe dazu berufen, allen Mitgliedern der Familie eine umfassende und gleichmäßige Entwicklung zu gewährleisten ${ }^{39}$.

Eine integrale und ganzheitliche Erziehung des Menschen in der Familie muss auf dem Personalismus basieren. Deshalb legte Johannes Paul II. großen Wert auf die Feststellung, dass eine so begründete familiäre Erziehung zwar eine Notwendigkeit, darüber hinaus ein Geschenk und ein Angebot, niemals jedoch etwas Aufgezwungenes zu sein habe ${ }^{40}$. Jeder Mensch, der über die Würde der

${ }^{38} \mathrm{Vgl}$. Gratissimum sane 16; Familiaris consortio 28.

${ }^{39}$ Vgl. Familiaris consortio 25; B. Mierzwiński, Mężczyzna-mąż-ojciec, Otwock 1996, S. 197-201; M. Styczyńska, Wptywy nieobecności ojca na rozwój i zachowanie dziecka w wieku przedszkolnym, in: M. Duda (Hrsg.), Rodzina wobec zagrożeń, Kraków 2008, S. 99-106; T. Sosnowski, Zainteresowanie ojców procesem wychowania dzieci w rodzinach miejskich, in: B. Muchacka (Hrsg.), Rodzina w kontekście wspótczesnych problemów wychowania, Kraków 2008, S. 251-261; J. Zawisza-Smejlis, Rola ojca w procesie wychowania dziecka niepetnosprawnego, in: M. Duda (Hrsg.), Rodzina wobec zagrożeń, Kraków 2008, S. 189-197; M. Piotrowska, Wspomnienia rozwodu rodziców w narracjach ich dorostych dzieci, in: A. Ładyżyński (Hrsg.), Rodzina we współczesności, Wrocław 2009, S. 291-301; M. Prokosz, Straty dziecka wychowywanego poza rodzina, in: A. Ładyżyński (Hrsg.), Rodzina we współczesności, Wrocław 2009, S. 303-311.

40 Vgl. P. Kaźmierczak, Personalistyczna koncepcja wychowania nauczaniu Jana Pawła II, Kraków 2003; A. Rynio (Hrsg.), Wychowanie chrześcijańskie. Między tradycja 
Person verfügt, besitzt damit von Natur aus die Freiheit das Gute auszuwählen. Er wird das Leben schätzen, Selbstbeherrschung üben und die Rechte seiner Mitmenschen achten. Der Erzieher soll also die naturgegebene Freiheit und die Fähigkeit zu einer wohl überdachten Wahl des zu erziehenden jungen Menschen berücksichtigen und diesem keine Entscheidung aufzwingen. Bei einer personalistischen Erziehung wird der Freiheitsbegriff jedoch anders verstanden als in der kritischen Pädagogik. Denn ein Erzieher, der den Entwicklungsstand des Zöglings respektiert, wird vor diesem nicht die gesamte Palette der Handlungsmöglichkeiten oder Ziele aufrollen, unter denen dieser sich das Passende auswählen sollte. Der Erziehungsprozess wird auf der Grundlage des Personalismus im eindeutigen und analogen Sinn aufgefasst, weil der Erzieher dank seiner Erfahrung zunächst das herauslesen wird, was für den Zögling gut ist, was dieser benötigt und was er anstreben soll. All das, was er dann selbst aufspürt, wird er dem Zögling in Form eines gründlich überlegten Vorschlags unterbreiten. Auch wenn der junge Mensch das Angebot ablehnt, weiß er, dass er von seinem Erzieher dennoch weiter bejaht und angenommen wird ${ }^{41}$. Die Erziehung besteht also in einer Begegnung der Person des Erziehers mit der des Zöglings, des Meisters mit dem Schüler. Sie ist ihre gemeinsame Wanderung hin zur Wahrheit, zum Guten und Schönen in der Zusammenarbeit und im Streben nach gegenseitigem Verständnis ${ }^{42}$. Die ganzheitliche Erziehung jedes Menschen ist ein wechselseitiger Prozess, der von der Familie, der Arbeit sowie der Kultur abhängt und in welchem die Eltern als Erzieher ihrerseits gewissermaßen erzogen werden ${ }^{43}$. Wenn man sich als Subjekt an das Kind wendet, kommuniziert man ihm auf diese Weise, dass von diesem ebenfalls ein Verhalten als Subjekt

a współczesnościa, Lublin 2007; A. Rynio, Integralne wychowanie w myśli Jan Pawła II, Lublin 2004; M. Nowak, T. Ożóg, A. Rynio (Hrsg.), W trosce o integralne wychowanie, Lublin 2003; J. Mastalski, Szkolne interakcje zaburzająe skuteczne wychowanie, Kraków 2005; J. Mastalski, Zarys teorii wychowania, Kraków 2002.

${ }^{41}$ Vgl. S. Chrobak, Obraz ucznia w ujęciu personalizmu, in: A. J. Sowiński, A. Dymer (Hrsg.), Szkoła katolicka na przełomie wieków, Szczecin 2001, S. 43; J. Dobrzyńska, Pedagogika personalistyczna, „Wychowawca” 7 (1999) Nr 9, S. 23; M. Łobocki, Przedmiotowe traktowanie uczniów, „Wychowawca” 6 (1998) Nr 7-8, S. 36.

${ }^{42}$ Vgl. Jan Paweł II, Nie lękajcie się zawierzyć Chrystusowi. Przemówienie do młodzieży, Tor Vergata, 19 VIII 2000, in: Cz. Drążek (Hrsg.), Jan Paweł II. Wskazania na trzecie tysiaclecie, Kraków 2002, S. 272-277.

${ }^{43}$ Vgl. Gratissimum sane 16; S. Dziekoński, Formacja chrześcijańska dziecka $w$ rodzinie wnauczaniu Kościoła, Warszawa 2006; A. Potocki, Wychowanie religijne w polskich przemianach, Warszawa 2007. 
erwartet wird, auf allen Ebenen und in allen Bereichen des Lebens ${ }^{44}$. Johannes Paul II. betrachtet in seinen Lehrschreiben die Erziehung als dualen Prozess, bei dem einerseits der Erzieher, die unterschiedlichen Erziehungsinstitutionen oder weitere Lebensumfelder auf den Zögling einwirken, andererseits jedoch auch der zu erziehende junge Mensch als Subjekt agiert. Er wird in seiner Würde als Person respektiert und ernst genommen und kann damit nach seinen Fähigkeiten Verantwortung für die Gemeinschaftübernehmen. Erziehung impersonalistischen Sinn setzt aber auch voraus, dass die Dynamik und die Regeln des Heranwachsens und der Entwicklung des Menschen genauestens bekannt sind. Darüber hinaus erfordert sie Achtung und Respekt gegenüber der nicht immer vorhersehbaren Prädispositionen des Menschen. Es geht dabei um Handlungsweisen, die nicht nur die Anforderungen nach Wahrheit, Wohlergehen, Vertrauen in sich selbst und in Gott beinhalten, sondern auch auf das persönliche Glück, auf Gerechtigkeit, auf zwischenmenschliche Solidarität, auf die Verbindung von Moral und Allgemeingut, auf die ganzheitliche Entwicklung und die Freiheit der Person ausgerichtet sind ${ }^{45}$. Für Johannes Paul II. war der allgemeine Grundsatz der persönlichen Subjektivität als Norm für die Beziehungen zwischen Personen von höchster Bedeutung: „Die Aufgabe, welche die Eltern in dem Kind von Anbeginn an und alle Jahre seines Heranwachsens hindurch entdecken, besteht darin, diesen kleinen - sich schrittweise entwickelnden Menschen - mit reifer Menschlichkeit zu beschenken"46. Unter allen Aufgaben der familiären und personalistischen Erziehung nehmen diejenigen den höchsten Stellenwert ein, die dem Kind dabei helfen wollen, die Wahrheit seiner persönlichen Berufung und den Sinn seines Lebens zu ergründen. Eine derartige Erziehung soll das Kind dazu bewegen, selbstständig in Verständnisbereitschaft, in der Wahrheit, im Guten, in der Freiheit und im Verantwortungsbewusstsein heranzuwachsen ${ }^{47}$.

${ }^{44}$ Vgl. Familiaris consortio 39; E. Osewska, To Educate in a Diversified Europe, „The Person and the Challenges" 1 (2011) Nr 1, S. 71-88; E. Osewska, Erwartungen an die katholische Schule in einem postmodernen Zeitalter, „The Person and the Challenges” 1 (2011) Nr 2, S. 95-108.

${ }^{45}$ Vgl. A. Rynio, Integralne wychowanie w myśli Jana Pawła II, Lublin 2004, S. 360-375. S. 22.

${ }^{46}$ K. Wojtyła, Rodzicielstwo a communio personarum, Ateneum Kapłańskie 67 (1975) Nr 1,

${ }^{47}$ Vgl. E. Osewska, J. Stala, Catholic School. Polish Perspective, "Rivista Lasalliana" 75 (2008) $\mathrm{Nr}$ 2, S. 241-246; J. Stala, Familie und Schule: Zwei Erziehungsumfelder und Ihre Rolle im Rahmen der Erziehung, „Roczniki Teologiczne” 55 (2008), T. 8, S. 101-112; J. Stala, Die Erzieherischen Umfelder und Ihre Rolle im Rahmen der Erziehungsaufgaben, „Studia Teologiczno-Historyczne Śląska Opolskiego" 27 (2007), S. 375-383; J. Stala, Die Familie als Erziehungsgemeinschaft in der Perspektive des Familienkatechumenats, „Vox Patrum“ 27 (2007), T. 50-51, S. 487-496; J. Stala, Istotne rysy edukacji religijnej odczytane $w$ refleksji nad nauczaniem Jana Pawla II, „Ateneum Kapłańskie" 148 (2007) 3 (589), S. 524-530; J. Stala, Wychowanie do matżeństwa i rodziny na 
Die Familie formt den Menschen, der ihr angehört - sie bildet sein Gewissen, seine Wertehierarchie und seine persönliche Art und Weise sich dem Nächsten zuzuwenden ${ }^{48}$.

Bei der Erfüllung ihrer überaus bedeutsamen Erziehungsmission soll sich die Familie jedoch nicht in sich selbst einschließen. Vielmehr ist sie dazu aufgerufen sich im Kleinen wie auch im Großen der gesamten Gesellschaft $\mathrm{zu}$ öffnen. Wenn sie sich ihrer Verantwortung um das Wohlergehen des Nächsten und für die Gerechtigkeit in allen sozialen Strukturen bewusst ist und in dieser Überzeugung aktiv wird, kann sie einen wesentlichen Beitrag zur Personalisierung des Menschen auf allen Ebenen leisten. Auf diese Weise wird die Familie zur Schule derjenigen sozialen Tugenden, die für das Leben und die Entwicklung der gesamten Gesellschaft entscheidend sind: eine Schule der Liebe und der Solidarität, der Gerechtigkeit, des Dialogs sowie aller menschlichen und christlichen Tugenden. Sie führt nicht nur in die Sphäre der humanen sondern ebenso in die Sphäre der geistlichen Werte ein. Gerade in der Familie findet die Person die erste und unersetzliche Schule für ein wahrhaft menschliches Leben ${ }^{49}$. Dieser Zusammenhang wird von J. Mastalski so unterstrichen: „Eine Erziehung, die nicht in die Welt der Werte einführt, ist in der Regel lediglich unvollständig und wenig erfolgreich, mehrfach sogar gedankenlos und schädlich für die Gesellschaft" ${ }^{50}$. In der Familie wird der Mensch bedingungslos angenommen, hier lernt er zu leben und seine Persönlichkeit schrittweise auszuformen $^{51}$. Eine integrale Erziehung auf der Grundlage des Personalismus bezieht alle Sphären der menschlichen Existenz mit ein, insbesondere auch die transzendente. Deshalb war es dem Heiligen Vater Johannes Paul II. ein

miarę XXI wieku, in: A. Offmański (Hrsg.), Małżeństwo i rodzina w panoramie współczesnych systemów, Szczecin 2006, S. 183-205.

${ }^{48}$ Vgl. Familiaris consortio 37; Gratissimum sane 2; J. Majka, Wychowanie chrześcijańskiewychowaniem personalistycznym, in: F. Adamski(Hrsg.), Wychowanie wrodzinie chrześcijańskiej, Kraków 1982, S. 41-45; J. Roztworowski, Integralny zwiazek czynnika nadprzyrodzonego i naturalnego $w$ wychowaniu chrześcijańskim, in: F. Adamski (Hrsg.), Wychowanie w rodzinie chrześcijańskiej, Kraków 1982, S. 56-68; F. Adamski, Prawda jako zasada życia społecznego, „Wychowawca” 6 (1998) Nr 11, S. 28; A. Rynio, Integralne wychowanie w myśli Jana Pawła II, Lublin 2004, S. 235; J. Mastalski, Chrześcijanin wobec agresji w rodzinie, Kraków 2006.

${ }^{49} \mathrm{Vgl}$. E. Osewska, Edukacja religijna w szkole katolickiej w Anglii $i$ Walii w świetle „Living and Sharing Our Faith. A National Project of Catechesis and Religious Education”, Tarnów 2008, S. 241.

${ }^{50}$ J. Mastalski, Samotność globalnego nastolatka, Kraków 2007, S. 290.

${ }^{51}$ Vgl. S. Chrobak, Koncepcja wychowania personalistycznego w nauczaniu Karola Wojtyty - Jana Pawła II, Warszawa 1999, S. 91-92; A. Rynio, Integralne wychowanie w myśli Jana Pawła II, Lublin 2004, S. 242. 
großes Bedürfnis, auf den erzieherischen Wert des persönlichen wie auch des gemeinschaftlichen Gebets in der Familie hinzuweisen. Das sakramentale Leben der Familie, die gemeinschaftliche Teilnahme an der Eucharistie, der Empfang des Bußsakraments und die Erfahrung von Versöhnung und Heilung leisten einen weiteren und unschätzbaren Beitrag zur Erziehung wie auch zur Selbsterziehung. Erst durch die Einbeziehung der geistlichen Dimension kann der Mensch zu einer lebensbejahenden Einstellung geführt werden, die vom Glauben an eine Wertehierarchie bestimmt und getragen ist ${ }^{52}$.

Der Mensch ist ein Wesen, das für Gottes Handeln und Gottes Initiative offen ist. Gott hat ihn in einer Gemeinschaft und für eine Gemeinschaft erschaffen, die alle Menschen mit Jesus Christus vereint. Eine communio personarum, die auf der Achtung jedes Menschen als Person basiert und die durch die Gnade Christi bereichert wird, wird zu einer Gemeinschaft in einer transzendenten, die Möglichkeiten des Menschen überschreitenden Dimension. In seiner Liebe offenbarte Gott dem Menschen einen kleinen Teil seines inneren Lebens, das auf der Liebe und der Einheit in der Dreifaltigkeit gründet. Gott in einer Person wäre nicht die Liebe. Gott - der Vater erkennt sich selbst so umfassend und vortrefflich, dass dieses Wissen zur Person wird - zum Sohn Gottes. Diese uralte Liebe des Vaters zum Sohn und die Liebe des Sohnes zum Vater ist so intensiv und vortrefflich, dass sie wiederum zur Person wird - zum Heiligen Geist. Das Wesen dieses dreifaltigen Lebens besteht im Austausch der Liebe, in gegenseitiger Hingabe und in der dankbaren Annahme dieses Geschenks. Im Heiligen Geist wird das innere Leben des Dreifaltigen Gottes zu einer ganzheitlichen Gabe, zum gegenseitigen Austausch der Liebe zwischen den Göttlichen Personen, durch den Heiligen Geist existiert es als Gabe ${ }^{53}$. Das Neue Testament verkündet

${ }^{52}$ Vgl. Gratissimum sane 18; Evangelium vitae 93; A. Rynio, Integralne wychowanie w myśli Jana Pawła II, Lublin 2004, S. 353-354; Z. Tyszka, Rodzina we współczesnym świecie, Poznań 2003; B. Czeredrecka, Rodzina jako środowisko życia i wychowania, in: U. Gruca-Miąsik (Hrsg.), Dziecko i rodzina. Społeczne powinności opieki i wychowania, Rzeszów 2007, S. 11-17; U. GrucaMiąsik, Rola rodziny w rozwoju i wychowaniu moralnym dzieci i młodzieży, in: U. Gruca-Miąsik (Hrsg.), Dziecko i rodzina. Społeczne powinności opieki i wychowania, Rzeszów 2007, S. 34-46; Jan Paweł II, Rodzice pierwszymi nauczycielami wiary. W czasie Mszy Świętej, podczas której papież udzielił I Komunii świętej, Cardiff, Wielka Brytania, 2 VI 1982, in: J. Żukowicz (Hrsg.), Dziecko w nauczaniu Jana Pawła II, Kraków 1985, S. 80-81.

${ }^{53} \mathrm{Vgl}$. Dominum et vivificantem 16. 
die Definition Gottes: Gott ist die Liebe ${ }^{54}$. Daher ist jede Form der Liebe aufs engste mit Gott verbunden und entströmt Ihm. Wir wollen einander lieben - so rief der hl. Johannes auf - denn die Liebe ist aus Gott, und jeder, der liebt, stammt von Gott und erkennt Gott ${ }^{55}$.

Zusammenfassend lässt sich bemerken, dass für Johannes Paul II. die Achtung des Menschen als Person der zentrale Punkt seiner pädagogischen Reflexionen war. Ausgehend davon entwickelte er sein Bild von der Familie, die für ihre Mitglieder zu einer Gemeinschaft des Lebens und der Erziehung werden soll. Zweifellos bildete die Genealogie der Person, in enger Verbindung mit der Ehe - dem geweihten Bund zweier Personen - die Basis von Anthropologie und Pädagogik des Heiligen Vaters. Für Johannes Paul II. erwächst aus diesem Bund die familiäre communio personarum, der unersetzbare Ort für die Personalisierung jedes menschlichen Wesens.

\section{Bibliography}

Bajda J., Rodzina miejscem Boga i czlowieka, Łomianki 2005.

Buxakowski J., Wprowadzenie do teologii duszpasterstwa rodzin, Pelplin 1999.

Cader S., Rodzina środowiskiem wychowawczym w świetle nauczania Jana Pawła II, Kraków 2004.

Chrobak S., Koncepcja wychowania personalistycznego w nauczaniu Karola Wojtyly Jana Pawta II, Warszawa 1999.

Czamara W., Przemiana religijno-moralna człowieka w nauczaniu Jana Pawła II, Poznań 1997.

Czarny J., Jana Pawła II wizja cywilizacji miłości, Wrocław 1994.

Drożdż M. (Hrsg.), Człowiek między losem a wyborem, Tarnów 2006.

Duda M. (Hrsg.), Rodzina wobec zagrożeń, Kraków 2008.

Gruca-Miąsik U. (Hrsg.), Dziecko i rodzina. Społeczne powinności opieki i wychowania, Rzeszów 2007.

Gryz K. (Hrsg.), Cztowiek droga Kościoła. Moralne aspekty nauczania Jana Pawła II, Kraków 2004.

Harwas-Napierała B. (Hrsg.), Rodzina jako wartość w rozwoju człowieka, Poznań 2009.

Kaźmierczak P., Personalistyczna koncepcja wychowania nauczaniu Jana Pawła II, Kraków 2003.

\footnotetext{
${ }^{54} \mathrm{Vgl} .1 \mathrm{~J} 4,8$.

${ }^{55} \mathrm{Vgl} .1 \mathrm{~J} 4,7$.
} 
Korzeniowska W., Murzyn A., Lukasova-Kantorkova H. (Hrsg.), Rodzina dla Europy czy Europa dla rodziny?, Kraków 2006.

Kupny J., Łuczak M. (Hrsg.), Testament społeczny Jana Pawła II, Katowice 2006.

Laskowski J., Matżeństwo wspólnota miłości, Warszawa 1993.

Laskowski J., Trwałość wspólnoty matżeńskiej, Warszawa 1987.

Lubowicki K., Duchowość matżeńska w nauczaniu Jana Pawła II, Kraków 2005.

Ładyżyński A. (Hrsg.), Rodzina we współczesności, Wrocław 2009.

Majdański K. (Hrsg.), Teologia matżeństwa i rodziny, Warszawa 1980.

Mastalski J., Samotność globalnego nastolatka, Kraków 2007.

Mastalski J., Szkolne interakcje zaburzajace skuteczne wychowanie, Kraków 2005.

Mierzwiński B., Dobowska E. (Hrsg.), Oblicze współczesnej rodziny polskiej, Kraków 2003.

Mierzwiński B., Mężczyzna - mąż - ojciec, Otwock 1996.

Muchacka B. (Hrsg.), Rodzina w kontekście współczesnych problemów wychowania, Kraków 2008.

Muszyński W., Sikora E. (Hrsg.), Matżeństwo i rodzina w ponowoczesności. Szanse zagrożenia - patologie, Toruń 2008.

Osewska E., Edukacja religijna $w$ szkole katolickiej $w$ Anglii $i$ Walii $w$ świetle „Living and Sharing Our Faith. A National Project of Catechesis and Religious Education”, Tarnów 2008.

Osewska E., Erwartungen an die katholische Schule in einem postmodernen Zeitalter, „The Person and the Challenges” 1 (2011) Nr 2, S. 95-108.

Osewska E., Stala J., Catholic School. Polish Perspective, "Rivista Lasalliana" 75 (2008) Nr 2, S. 241-246.

Osewska E., To Educate in a Diversified Europe, „The Person and the Challenges” 1 (2011) Nr 1, S. 71-88.

Petryk P., Ku wspólnocie życia i miłości, Lublin 1998.

Potocki A., Wychowanie religijne w polskich przemianach, Warszawa 2007.

Rynio A. (Hrsg.), Wychowanie chrześcijańskie. Między tradycja a wspótczesnościa, Lublin 2007.

Rynio A., Integralne wychowanie w myśli Jana Pawła II, Lublin 2004.

Ryś M., Jankowska M. (Hrsg.), W trosce o rodzinę, Warszawa 2007.

Stala J., Die Erzieherischen Umfelder und Ihre Rolle im Rahmen der Erziehungsaufgaben, „Studia Teologiczno-Historyczne Śląska Opolskiego” 27 (2007), S. 375-383.

Stala J., Die Familie als Erziehungsgemeinschaft in der Perspektive des Familienkatechumenats, „Vox Patrum“ 27 (2007), T. 50-51, S. 487-496.

Stala J., Die Transzendenz als bestimmendes Merkmal der Person in der Anthropologie und der Pädagogik Johannes Pauls II., „The Person and the Challenges” 2 (2012) nr 1, S. 61-75. 
Stala J., Familie und Schule: Zwei Erziehungsumfelder und Ihre Rolle im Rahmen der Erziehung, „Roczniki Teologiczne” 55 (2008), T. 8, S. 101-112.

Stala J., Familienkatechese in Polen um die Jahrhundertwende. Probleme und Herausforderungen, Tarnów 2008.

Stala J., Osewska E. (Hrsg.), Rodzina - bezcenny dar i zadanie, Radom 2006.

Swieżawski S., Istnienie i tajemnica, Lublin 1993.

Tyszka Z., Rodzina we współczesnym świecie, Poznań 2003.

Wilk J., Pedagogika rodziny. Zagadnienia wybrane, Lublin 2002.

Wojtyła K., Rodzina jako communio personarum, „Ateneum Kapłańskie” 66 (1974) Nr 83 , S. 347-361. 
